\title{
From the editors of the issue
}

The editors invite readers to a new and exciting issue of the Zeitschrift für Australienstudien: Australian Studies are becoming increasingly transnational not merely in relation to the background of its scholars but also in terms of academic themes. Like other settler societies, Australia has never been an isolated island. Rather, it has been shaped by diversity and global discourses. This diversity has been of geopolitical, cultural as much as literary influence. Despite this highly heterogeneous background, Australian Studies have nonetheless often been practised within national frameworks. Comparisons, let alone transnational approaches, have been relatively rare - at least from the perspective of systematic research. Today, Australian Studies scholars are experiencing an innovative shift in their various fields of research: translation studies, comparative historical and literary studies and transnational Indigenous Studies are starting to appear, complementing established research.

This volume of the Zeitschrift für Australienstudien clearly reflects this new and intellectually highly promising change.

Adi Wimmer has transnational structures of analysis in mind as he pursues a comparative approach in his biographically orientated article on Elizabeth Jolley. In his essay "'Don't Forget About Electra!' Elizabeth Jolley's Life and its Reflection in her Works" Wimmer retraces parts of Jolley's family history and also elaborates on the impact this biographical research exerts on the understanding of Jolly's writings. Aside from this innovative approach to literary studies, this article is of great transnational importance. Elizabeth Jolly was born in Austria: her writing reflected Australian contexts as much as Central European discourses.

Rob Amery follows a similar path of transnational analysis: He explores the work of four German missionaries from the Dresden Mission Society in the early nineteenth century and their legacy in 
documenting the languages and cultures of the Kaurna, Ngarrindjeri and Barngarla peoples of South Australia. Amery's differentiated approach shows the complexity of inter-cultural engagement between Indigenous peoples and Germans in the eighteenth century and conceives inter-racial engagement not as merely oppositional. His study demon-strates the importance of diversifying non-Indigenous agents in Australian history.

Eva Meidl visualizes the historical approach to transfer intercultural knowledge - at least in one way: She illustrates how iconic pictures were used to build up (European) imaginations of a far-distant continent. In her article "An unofficial view: Johann Wäber's/John Webber's portrayals of Aboriginal Tasmanians" Meidl offers a rich insight into the racial perceptions of late eighteenth century Europe. These perceptions, as the paintings illustrate, were not devaluing - a result of immense importance for studies on racial representations in general. Meidl goes further than studying the mere racial representations but places Wäber's/Webber's representations in the context of eighteenth century European interest in seemingly exotic races and cultures.

Jörg-Dieter Riemenschneider's article "Aotearoa New Zealand Landscape Poetry: A Cultural and an Evocritical Reading" constitutes an equally new approach: It presents a reading of selected Aotearoa New Zealand poems from an evolutionary psychological perspective, arguing for cross-cultural, biologicallyordained patterns of perceiving Aotearoa New Zealand landscape. The study looks at how such perceptions have been used by contemporary Maori poets. Riemenschneider employs a very careful and balanced approach to a contested field of study which could also be applied to Australian contexts.

Concerned with a New Zealand theme, Riemenscheider's text marks an important change in the scope of the Zeitschrift für Australienstudien which welcomes decidedly comparative approaches and Australia-Pacific-related topics in its future volumes. The consideration of New Zealand (and Pacific) themes 
does not delegitimize the studies on Australia but stands in the new tradition of transnational approaches.

Never before did authors and editors acknowledge the fact that Australia is part of the southern hemisphere in such an impressive way: As result, the 2012 issue introduces a new column which will strengthen comparative perspectives of research in the field of Australian Studies. The editors decided to add this new column, Hemisphere, in order to invite potential authors to extend their focus of research and to appreciate the evolutionary, cultural and historical interdependencies which characterize Australia's relationship with her neighbours. The view from outside is the key to the heart of Australian Studies: It helps to develop transnational views within the hemisphere. Although Riemenschneider's article is no comparative study, it enriches our understanding of landscape poetry - in New Zealand, Australia and in the Pacific sphere.

There is also a change in the editing of the Zeitschrift für Australienstudien. We wish to acknowledge Adi Wimmer's devoted work which has transformed a rather pioneering and local Newsletter into a fully peer-reviewed and internationally indexed journal. It is much harder to establish a journal than to keep its good reputation. We wish to honour Adi Wimmer's work by continuing the journal's traditions of rigorous refereeing policies and allowing considerable room for substantial review articles, while also further positioning the Zeitschrift für Australienstudien as a leading continental journal for Australian Studies. Meanwhile, our Association continues to issue a bi-annual electronic Newsletter which presents news, reports and debates on Australia's current affairs. Australianists can visit the e-Newsletter on www.australienstudien.org.

As part of the editorial change, we have pleasure to welcome three distinguished Australian academics as members of the journal's Advisory Board: Ann Curthoys (University of Sydney), Jeanine Leane (Australian National University) and Gerhard 
Fischer (University of New South Wales). In close collaboration with the members of the Advisory Board we look with confidence to a fresh and prosperous future for the Zeitschrift für Australienstudien.

Henriette von Holleuffer \& Oliver Haag (June 2012) 